\title{
GSM AND WIRELESS SENSOR NETWORK BASED SMART AUTOMATED IRRIGATION SYSTEM
}

\author{
Chimata Suhasini ${ }^{1}$, Diwakar R. Marur ${ }^{2}$ \\ M.Tech, Embedded Systems, SRM University, Chennai, India ${ }^{1}$ \\ Assistant Professor, SRM University, Chennai, India ${ }^{2}$
}

\begin{abstract}
The farmers working in the farm lands are solely dependent on the rains and bore wells for irrigation. Even if the farmland has a water-pump, manual intervention by the farmers is required to turn the pump ON/OFF whenever needed. Therefore using an Android application which helps the farmer to ON/OFF the motor without his physical presence in the field. This paper has real time sensing and control of an irrigation system. When the condition of water in the agricultural farm is abnormal then the system automatically switches OFF. Based on the soil moisture, through relay the pumping motor will be automatically switch on or off which saves the water and on the other hand the plant can get most appropriate water level which increases the productivity of the crop. Using GSM (Global System for Mobile communication) technology which is used to inform the user about the exact condition of the field. This information is passed onto the user request in the form of SMS (Short Message Service). The proposed system provides uniform and required water level for the agricultural farm and it avoids water wastage.
\end{abstract}

Keywords: GSM, Temperature sensor, Humidity sensor, Soil moisture sensor, Pump, Relay.

\section{INTRODUCTION}

Agriculture is the backbone of India. So, in India agriculture has been the most important priority in the economic development of the country. Major part of the expenditure is spent on agriculture alone and inspite of that farmer are not getting sufficient output. This project offers a simple solution to this problem by developing automated microclimate irrigation controllers with wireless capability assisted with low cost wireless sensor node [1]. Like temperature sensor and humidity sensor which senses the level of moisture content in the soil. Due to an unbalanced natural distribution of the rain water it is very difficult for farmers to monitor and control the distribution of water to agriculture field in the whole farm or as per the requirement of the crop.

The user communicates through SMS with the centralized unit. This centralized unit communicates with the system through SMS which will be received by the GSM with the help of the SIM (Subscriber Identity Module) card [2]. The motor is controlled by a simple manipulation in the internal structure of the starter. When the motor is started, a constant monitoring on soil moisture and water level is done and once the soil moisture is reached to particular level of the motor is automatically turned off and a massage is send to subscriber that the motor is turned off.

\section{Advantages of proper watering for plants:}

1) When irrigation becomes necessary and sufficient water should be applied so that the soil is wetted to the depth of four to six inches. This amount of water will vary with the soil texture, approximately one inch of water should thoroughly wet most soils to a depth of four to six inches [3].
2) Irrigate the field at any time during the day or night times. However, both day and night time watering have their advantages and disadvantages. The Midday watering can serve to cool the turf and reduce heat stress on hot summer days.

3) Night irrigation helps to conserve water because of the minimal evaporation at night. Unless disease will occur and actively damaging the field, there is little reason to avoid the night watering. The late afternoon or early morning watering may help to minimize evaporation without aggravating disease activity.

\begin{tabular}{|c|c|c|}
\hline Stages of growth & $\begin{array}{c}\text { Avg. water } \\
\text { requirement (mm) }\end{array}$ & $\begin{array}{c}\text { \% of total water } \\
\text { requirement } \\
\text { (approx.) }\end{array}$ \\
\hline Nursery & $50-60$ & 5 \\
\hline $\begin{array}{c}\text { Main field } \\
\text { preparation }\end{array}$ & $200-250$ & 20 \\
\hline $\begin{array}{c}\text { Planting to Panicle } \\
\text { initiation (PI) }\end{array}$ & $400-550$ & 40 \\
\hline $\begin{array}{c}\text { PI to flowering } \\
\text { Flowering to } \\
\text { maturity }\end{array}$ & $400-450$ & 30 \\
\hline Total & $100-150$ & 5 \\
\hline
\end{tabular}

Table I: Water requirement of rice crop at different growth stages [4].

Table I shows that the average water requirement in $\mathrm{mm}$ and percentage of total water requirement of rice crop at different stages of growth. Excess or limited or no water leads to reduction in yield. Rice a semi - aquatic plant 
requires near submergence. Submergence helps in suppressing weed growth and more availability of certain nutrients. Daily consumptive use of rice is $6-10 \mathrm{~mm}$. Total water requirement of rice is $1200-1400 \mathrm{~mm} .2000$ 3000 liters of water required to produce $1 \mathrm{~kg}$ rice. Highly brackish and saline water not good for irrigation. Perfect leveling can maintain uniform depth of water throughout field. Maintaining the water depths in the field as recommended for high water use efficiency and yield.

\begin{tabular}{|l|c|c|c|c|}
\hline Particular & Clay Loam & Silty Clay & Loam & Sandy Loam \\
\hline $\begin{array}{l}\text { Water } \\
\text { requirement }\end{array}$ & 1583 & 1602 & 1995 & 2261 \\
\hline Irrigation & 1125 & 1200 & 1500 & 1775 \\
\hline Runoff & 207 & 191 & 193 & 161 \\
\hline Percolation & $893(56 \%)$ & $870(54 \%)$ & $1187(60 \%)$ & $1515(67 \%)$ \\
\hline $\begin{array}{l}\text { Evapotranspi } \\
\text { ration }\end{array}$ & $690(44 \%)$ & $732(46 \%)$ & $808(40 \%)$ & $745(33 \%)$ \\
\hline
\end{tabular}

Table II: Requirement of water and losses of water in rice fields (in litres) [5].

Table II shows that the water requirement in litres and losses of water for different soil types in rice field. Percolation reduced to considerable extent by perfect leveling. Evaporation losses can be minimized by $50 \%$ when the soil is kept at saturation under leveled field conditions. Higher the transpiration higher the yield (a normal crop of $4.5 \mathrm{t} / \mathrm{ha}$ (tones/hectare) with an irrigation period of 100 days consumes $6 \mathrm{~mm}$ /day by transpiration [6]. $1.4 \mathrm{~mm} /$ day the yield decreases to $1 \mathrm{t} / \mathrm{ha}$ when it increases $10.5 \mathrm{~mm}$ the yield of crop will be increased upto $7.5 \mathrm{t} / \mathrm{ha}$ ). WSN (Wireless Sensor Network) based on ARM7 is utilized as a weather station network sending weather information. This research focuses on developing devices and also manages the tools, display and alert the weather or disaster warnings using the advantages of a wireless sensor network system. The wireless sensor network requirement to implement low cost, low power consumption, high performance and high sensitivity and the anti interference ability.

\section{SYSTEM ARCHITECTURE}

Fig.1 shows the block diagram of modern agricultural system. The parameters as discussed in the block diagram will monitor the field and gives the accurate results to the user. Here the new and important things are level sensors to monitor the soil conditions. If it is dry then this condition is very harmful to the plants. So, immediately the water will be released into the soil and make it wet. Temperature and humidity are useful in the case of monitoring the weather conditions. The LPC2148 microcontrollers are based on a 32-bit ARM7TDMI architecture with real-time emulation and embedded trace support that combine microcontroller with embedded high speed flash memory upto $512 \mathrm{~KB}$. Due to their tiny size, LPC2148 applications where miniaturization is a key requirement, such as accessing control and point-of-sale. Serial communications which interfaces ranging from a USB 2.0 full-speed device, multiple UART (Universal Asynchronous Receiver/Transmitter), SSP (Synchronous Serial Port ) SPI (Serial Peripheral Interface) to I2C-bus and on-chip SRAM (Static Random Access Memory) of 8 $\mathrm{KB}$ upto $40 \mathrm{~KB}$, make these devices that are very well suited for communication gateways and the protocol converters, soft modems, voice recognition and end imaging is low, providing large buffer size and also high processing power.

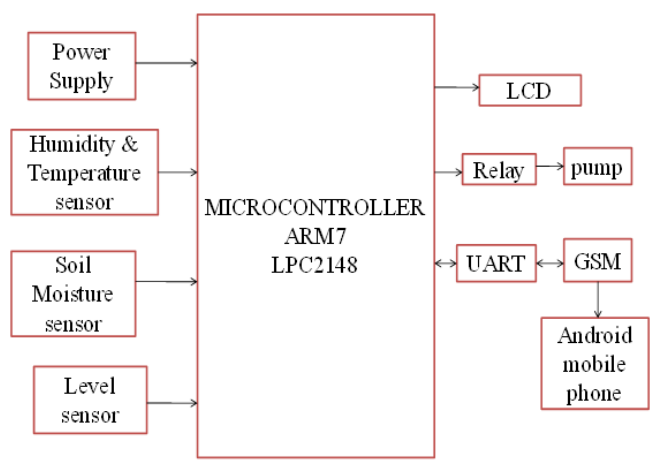

Fig. 1: Architecture of the proposed system

\section{A. Temperature Sensor}

Temperature sensor is connected to P0.30 pin. LM35 is a precision IC temperature sensor with its output proportional to the temperature (in ${ }^{\circ} \mathrm{C}$ ). The sensor senses the field temperature and is interfaced with microcontroller. With LM35, the temperature can be measured more accurate than thermistor. It also possess low self heating and do not cause more than $0.1{ }^{\circ} \mathrm{C}$ temperature rise in air. The operating temperature range is $-55^{\circ} \mathrm{C}$ to $150^{\circ} \mathrm{C}$.

\section{B. Humidity Sensor}

Humidity sensor is connected to $\mathrm{P} 0.31$ pin. SH 220 is the humidity sensor which is used to measure humidity of the field. This sensor senses the field humidity and is connected to the microcontroller. Set the points of humidity as $54 \%$ to $80 \%$ for standard irrigation. But it changeable according to the climate and the type of soil. Humidity measurement instruments usually rely on measurements of some other quantity such as temperature, pressure, mass or mechanical or electrical change in a substance which absorbs the soil moisture. By calculation and calibration, the quantities that are measured can lead to a Measurement of humidity.

\section{Soil moisture sensor}

Soil moisture sensor is connected to the port P0.29 pin. The soil moisture sensor is capacitive type. The sensor gives analog output of zero volts when there is $100 \%$ moisture and $5 \mathrm{~V}$ for $0 \%$ moisture. The sensor measures the dielectric constant of the soil in order to find its Volumetric Water Content (VWC). It obtains VWC by measuring the dielectric constant of the media through the utilization of the frequency domain technology. The dielectric constant of water is much higher than that of air or soil minerals, the dielectric constant of soil is sensitive 
measure of volumetric water content. The sensor has a low power requirement and also very high resolution. Due to this the ability to make many measurements (i.e. hourly) over a long period of time with minimal battery usage.

\section{Level sensor}

Level sensor is connected to P0.26 pin. Level sensors detect the level of substances that flow, in the form of liquids, slurries and powders. Such substances that flow to become essentially level in their containers (or other physical boundaries) due to gravity. The substance that measured can be inside a container or can be in its natural form (e.g. a river or a lake). The level measurement that can be either continuous or point values. The Continuous level sensors that can measure level within a specified range and determine the exact amount of substance in a particular place, while the point-level sensors indicate whether the substance is above or below sensing point. Latter detect levels that are excessively high or low. High accuracy and reliability.

\section{E. LCD (Liquid Crystal Display)}

LCD is having totally 16 pins. LCD is connected to $\mathrm{P} 0.22, \mathrm{P} 0.28$ and $\mathrm{P} 1.16$ to $\mathrm{P} 1.25$. It is used for displaying the parameters like temperature, humidity and soil moisture in the farm. It is a flat panel display, electronic visual display, or video display uses the light modulating properties of liquid crystals. Liquid crystals that does not emit light directly and are thin and flat and consume very small amount of power compared to LED displays and cathode Ray Tubes.

\section{F. Relay}

Relay is connected to P0.27 pin. It acts as an electrically operated switch. Many relays use an electromagnet for operating a switching mechanism mechanically, but the other operating principles are also preferred. They are used extensively in telephone exchanges and early computers to perform logical operations.

\section{G. UART}

UART0 is connected to P0.14 pin and UART1 is connected to P0.15. An UART is responsible for performing the main task in serial communications with the computers. The device changes incoming parallel information to serial data that can be sent on a communication line. The second UART that can be used to receive the information. UART performs all the tasks, timing, parity checking, etc. that is needed for the communication.

\section{H. GSM}

GSM Modem can accept any GSM network operator SIM card and acts as a mobile phone with its own unique phone number. The main advantage by using this modem will be that you can use its RS232 port to communicate and develop embedded applications. Applications like SMS Controlling, transferring the data, remote control and logging can be developed easily.

\section{Power Supply}

Power Supply is connected to P0.6 pin. It should deliver constant output regulated power supply. A 0-12V/500 mA transformer is used. The primary transformer is connected to main supply through on/off switch \& fuse for protecting from overload and protect from short circuit. The secondary transformer is connected to the diodes to convert $12 \mathrm{~V}$ of $\mathrm{AC}$ to $12 \mathrm{~V}$ of $\mathrm{DC}$ voltage. And is filtered by the capacitors, which is further regulated to $+5 \mathrm{~V}$, by using IC 7805. The designed components need 5V supply to work whereas the arm processors need $3.3 \mathrm{~V}$ supply. So by giving $3.3 \mathrm{~V}$ from the LM317. The device can provide $3.3 \mathrm{~V}$ to the processor.

\section{J. Android Phone}

An android phone that controls the Irrigation system, which could gives the facilities because to maintain uniform environmental conditions. This enables users to take advantage of the globally deployed GSM networks with its low SMS service cost to use mobile phones and simple SMS commands to manage the irrigation system. It is possible for users to use SMS to monitor directly the conditions of their farmland, schedule the water needs for crops, automatically water control, and also set control operational conditions in accordance with the water needs of crops.

\section{K. Pump}

The system which is used microcontroller to automate the process of water pumping in an over-head tank storage system and has the ability to detect the level of water in a tank, switch on/off the pump accordingly and display the status on an LCD screen.

\section{REMOTE CONTROL OF PUMP THROUGH GSM MODULE}

Remote control of pump through GSM module if moisture is less than threshold value then turn on the motor pump otherwise turn off the pump if already started otherwise do nothing.

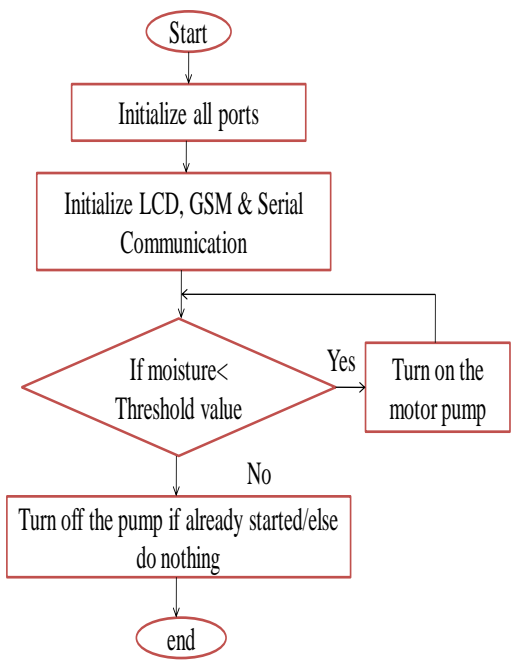

Fig. 2: Flowchart for controlling the motor through GSM module

Flowchart in the fig. 2 explains how the motor is controlled with the GSM module. This GSM module is used to check whether the moisture content around the 
field area. The soil moisture sensor that is connected to the LPC2148 microcontroller which in turn is connected to the water pump that senses the moisture surrounding the farmer's field area. If the moisture is below the threshold value that is mentioned, the water pump automatically on the switch. Else if the moisture rate is above the threshold value then the water pump turned off. The Humidity Mode which can be set by sending an SMS as SET1 to the GSM modem in the embedded system connected to the system.

\section{EXPERIMENTAL RESULTS}

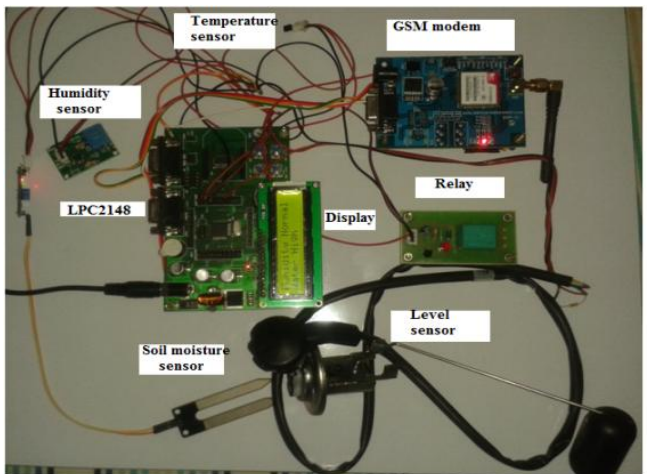

Fig. 3: Snapshot of the proposed system hardware

Fig. 3 shows that the temperature, soil moisture, humidity and level sensors will send the input data to the ARM LPC2148 microcontroller according to the environment and values are displaying on LCD. The level sensor which senses the water content of the plant whether water level is high or low and also displaying on LCD when water reaches at particular level of the plant automatically the motor stops running. The GSM sends the data to ARM7 which is also continuously receives the data from sensors in some form of codes. After processing, the data is displayed on the LCD. When the microcontroller will get any signal may be it will on or off it says the respective action. If it is on relay then it should get activated because the relay fault is connected to the microcontroller. The microcontroller which controls the operation through some activation command. Those commands were written in the program and are used easily by the end user (farmer) through the mobile phone services. Through those commands the microcontroller gives the desired output.

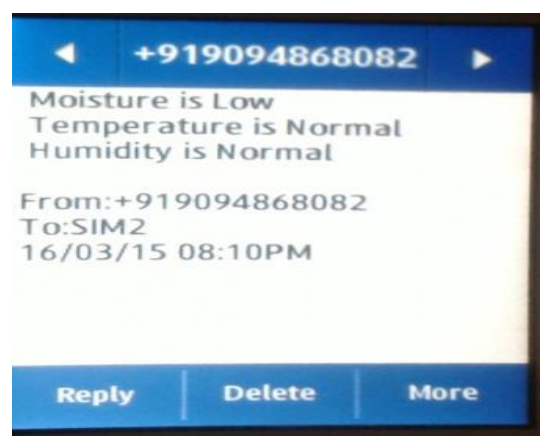

Fig. 4: Snapshot of android mobile receives the atmospheric conditions through GSM

Fig. 4 shows that the user communicates with the centralized unit through SMS which will be received by the GSM with the help of the SIM card. The GSM sends this data to ARM7 microcontroller which is continuously receives the data through sensors. If power is available sensor which detects the current and intimates farmer through SMS. Switch ON the motor through missed call or message by the farmer.

\section{CONCLUSION}

Irrigation in agricultural areas has extremely important. Increasing the demand for water resources, Usage of water resources is optimal which has been provided with greater extent by automation technology. Since earlier days farmer is supposed to visit their agricultural land and check the moisture content of soil manually. To avoid more human efforts this technology used. It allows the user to monitor and also maintain the moisture remotely regardless of time. It is really effective and economic way to reduce human effort and water wastage in agriculture land. Current problems in agriculture are reduced water level in land and availability of human resource [8]. So, as explained the mobile irrigation system can help farmer in many ways. The system has a huge demand and future scope too. It allows a lot of development within it and leads to the standard and useful system which can be used vary widely in agricultural field. Thus, project is proposed out using ARM7TDMI core with the help of GSM technologies.

\section{FUTURE ENHANCEMENTS}

By developing a Smart Wireless Sensor and by using upcoming techniques farmer can increase his profit by solving different problems that are faced in his routine life. And also to involve ARM - Controller with a video capturing by using an MMS facility about the crop position and at the same time sending video to the farmer.

\section{REFERENCES}

11] Kim, R. G. Evans, and W. M. Iversen, "Remote sensing and control of an irrigation system using a distributed wireless sensor network," IEEE Trans. Instrum. Meas., vol. 57, no. 7, pp. 13791387, Jul. 2008

[2] Zhang, F., Yang, M., and Ying, H., The application of GSM communication in agricultural automation, Journal of Technology for Agriculture, vol. 1, no. 1, 2004.

[3] W. A. Jury and H. J. Vaux, "The emerging global water crisis: Managing scarcity and conflict between water users," Adv. Agronomy, vol. 95, pp. 1-76, Sep. 2007

[4] P. Doll, S. Siebert, Global modeling of irrigation water requirements. Water Resources Research, vol. 38, no. 4, 2002.

[5] Kar, G.a.V., H.N., "Climatic water balance, probable rainfall, rice crop water requirements and cold periods in AER 12.0 in India", Agricultural Water Management, vol. 72, no. 1, pp. 15-32, 2005

[6] S. L. Davis and M. D. Dukes, "Irrigation scheduling performance by evapotranspiration-based controllers," Agricult. Water Manag., vol. 98, no. 1, pp. 19-28, Dec. 2010.

[7] G. Yuan, Y. Luo, X. Sun, and D. Tang, "Evaluation of a crop water stress index for detecting water stress in winter wheat in the North China Plain," Agricult. Water Manag., vol. 64, no. 1, pp. 29-40, Jan. 2004

[8] I. Singh and M. Bansal, "Monitoring Water Level in Agriculture using Sensor Networks", International Journal of Soft Computing and Engineering, pp. 202-204, November 2011.

[9] Gautam, I., and Reddy, S. R. N.," Innovative GSM-Bluetooth based remote controlled embedded system for irrigation", International Journal of Computer Applications, vol. 47, no. 8, 2012.

[10] [10] K. S. Nemali and M. W. Van Iersel, "An automated system for controlling drought stress and irrigation in potted plants," Sci. Horticult., vol. 110, no. 3, pp. 292-297, Nov. 2006. 